\title{
NOTAS BIBLIOGRÁFICAS
}

Nicholas F. Gier, Wittgenstein and Phenomenology, New York: SUNY Press, 1981 ; xix +268 pp.

Este libro pretende abordar un tema importante en la historia de la filosofía del siglo XX. Tal como han destacado muchos comentadores, la filosofía de Wittgenstein guarda una gran similitud con algunos aspectos de la fenomenología de Edmund Husserl. Por ejemplo, el concepto de una sintaxis lógica o una gramática lógica que aparece en la sección 3.325 del Tractatus es muy similar al concepto de gramática lógica según Husserl la formula en sus Investigaciones lógicas. No ha recibido mucha atención el hecho de que el propio Wittgenstein hay a sido un fenomenólogo confeso en 1929. En efecto, defiende entonces que los fenómenos de la experiencia inmediata por si solos pueden dar cuenta de las reglas de la gramática. Es evidente que debemos estudiar este período en el pensamiento de Wittgenstein si deseamos entender correctamente el concepto de gramática que tan importante llega a ser en su úl tima etapa. También es importante hacerlo para poder abrir ventanas entre la modalidad filosófica anglosajona y la así llamada continental.

Desafortunadamente, no hallamos tal estudio en el libro de Gier. Si bien la contraportada afirma que es "el primer estudio filosófico profundo de la fenomenología de Wittgenstein", es muy probable que muchos lectores no acepten fácilmente la idoneidad del calificativo "profundo". Gier nos ofrece un panorama de una buena sección de la filosofía del 1930 al 1960 . Es interesante; pero no da en el clavo. Declara que su objetivo es "surcar" hasta "la modalidad existencial" de Wittgenstein y reproducir "el tono y el acento" de su obra (p. 4), para entonces pasar a "discutir en detalle lo que Wittgenstein quiere decir por fenomenología y compararlo con el pensamiento de Husserl, Heidegger y Merleau-Ponty" (p. 5). Anuncia su tesis de inmediato: la fenomenología de Wittgenstein es una fenomenología de la vida. Así, pues, nos sentimos autorizados a suponer que su tratado se ha de dividir en dos partes. Una vendría a ser la exégesis de la fenomenología de Wittgenstein, mientras que la otra vendría a ser el contraste de tal fenomenologia con Husserl, Heidegger y Merleau-Ponty. Gier no ofrece lo primero; lo cual constituye el mayor defecto de su libro. Echamos de menos la consideración de temas tales como lo que Wittgenstein entiende por su propia fenomenología; por qué la adoptó; su papel en el alejamiento respecto del Tractatus; por qué no hallamos trazas de ella explicitamente en los escritos posteriores; etc. En resumen, Gier no analiza la doctrina que hace de Wittgenstein una especie de fenomenólogo ni aquello que motivó este giro en su pensamiento. Es éste un defecto muy 
serio. Una tarea tal no sólo se halla implícita en el programa del propio Gier, sino que es propedéutica de lo que desea realizar. Un estudio de Wittgenstein en tanto fenomenólogo y todo intento de entablar enlaces con otros fenomenólogos, debe ir precedido del análisis de lo que constituye lo primero. Gier da por sentado que todos conocemos la fenomenología de Wittgenstein y procede a trazar paralelos y diferencias con otras fenomenologías. Utilizando una frase común entre los filósofos anglosajones, se podría decir que Gier is all over the place. Vayamos por partes:

1. Wittgenstein y Husserl: Gier asevera que "con toda probabilidad" Wittgenstein "se hallaba bajo la influencia de Husserl" a tal grado que Philosophische Bemerkungen se adhiere a la fenomenología de este último (p. 81). Añade que Wittgenstein dispone de "un método trascendental. . . para intuir las esencias de modo directo" (p. 94) y que "definitivamente hace uso de la epoché" (p. 90). Según Gier, Wittgenstein define la realidad como "experiencia inmediata" (p. 89). Ningún tipo de análisis de textos avala estas afirmaciones y otras afines a ellas.

2. Wittgenstein sostiene la síntesis a priori: Gier cree que Wittgenstein no sólo se adhiere a la síntesis a priori, sino que "es razonable suponer que todas las proposiciones gramaticales son sintétic as a priori" (p. 185). Asevera, además de tesis tan atrevidas como la segunda parte de lo anterior (hay evidencia para la primera parte, aunque Gier la ignora casi completamente), que Wittgenstein ubica la gramática en una "lógica material" (p. 163) y que "hubiese" dividido toda la filosofía en un bando defensor de la sintesis a priori y en otro defensor de las oraciones analíticas. No se ofrece evidencia alguna para respaldar esta afirmación.

3. La experiencia prepredicativa: Esta es una de las tesis más aventuradas de Gier. Sostiene que Wittgenstein defiende un "regreso" a "los orígenes preepistemológicos en el mismo sentido que Heidegger reclama que los. .. problemas epistemológicos deben rastrearse a. . . la analítica existencial del Dasein" (pág. 199). Hay aseveraciones que intentan asimilar el Tractatus a la filosofía de Heidegger; fallan sobre todo al tratar de que los términos técnicos tales como Sachverhalt, Tatsachen y otros admitan una interpretación inspirada en El ser y el tiempo.

4. Wittgenstein es un fenomenólogo existencial: Gier afirma que el Umgebung de Wittgenstein es como la Lebenswelt de los fenomenólogos. Según Gier, Wittgenstein sostiene que un "ambiente" hace posible que los seres humanos entren a compartir juegos lingüisticos y formas de vida no compartidas por los animales. Adernás, que las formas de vida dan lugar a categorias historicoculturales tales como las del Dasein de Heidegger. "Nos hallamos en un mundo-Dasein", dice Gier como exégresis de Wittgenstein (p. 43). Asevera que para Wittgrenstein "la filosofía de la vida es más importante que la filosofía del lenguaje" (pp. 69-70), frase que, dada la ausencia de una clara explicación de lo que desea comunicar, nada dice. 
5. La fenomenología de Wittgenstein es una morfología de la cultura: Los acontecimientos culturales determinan las verdades gramaticales a tal grado - cree Gier - que "la verdad de una aseveración es contextual y depende de factores culturales" (pág. 155). Añade: "Wittgenstein cree que las leyes de la lógica son como las leyes de la sociedad".

6. Miscelánea: Wittgenstein concurre con Hegel en que la razón se halla sujeta a las condiciones de la historia y de la sociedad. EI "método trascendental" de Wittgenstein nos permite evaluar el conductivismo de Skinner. La fenomenología de Wittgenstein es similar a la hermenéutica de Gadamer. Hay paralelos y diferencias con Mauthner, Schleiermacher y otros.

La magnitud de la empresa de Gier es evidente. No resulta sorprendente que su obra se halle tan poblada de defectos. Tal como el lector puede entrever, Gier utiliza pasajes de Wittgenstein fuera de contexto, sin preocuparse por las dificultades hermenéuticas que ellos plantean. Gran parte de su argumentación consiste en menciones de otros autores.

Gier debió haber tenido en cuenta una importante diferencia (que él mismo muestra conocer): la fenomenología de la experiencia prepredicativa de la fenomenología tradicional es diferente de la fenomenología lingǘstica que Wittgenstein defiende. Recuérdese el pasaje número 90 de Investigaciones filosóficas:

Tal parecería como si nos dispusiésemos a penetrar en los fenómenos. Nuestra investigación, sin embargo, se halla destinada a investigar las clases de aseveraciones. [La traducción no es exacta.]

$\mathrm{Y}$, de manera consistente con esta insistencia en el lenguaje como vehículo de acercamiento a la realidad, Philosophische Bemerkungen dice explícitamente que el modo de lograr una "representación inmediata de la experiencia inmediata" es describiendo "la clase de los lenguajes que cumplen su cometido" (sección 1). Estas referencias bastan para disipar la tentación de considerar que la fenomenología de Wittgenstein es de la experiencia prepredicativa. Por cierto, como ejemplo del modo en que Gier no presta atención al texto de Wittgenstein, sépase que cuando hace referencia al pasaje citado de Philosophische Bemerkungen, lo interpreta en sentido contrario a las palabras del propio Wittgenstein.

Fn resumidas cuentas, Gier no sólo no ha ofrecido un estudio del Wittgenstein fenomenólogo, sino que lo que presenta se halla plagado de malinterpretaciones. Todavía resta por ejecutar el tan necesario estudio de la fenomenología de Wittgenstein.

Carlos H. Soto 